\title{
New Thinking of Human Resource Management in the Internet Era
}

\author{
Yun Liu \\ Huanghe Science \& Technology College; Zhengzhou 450006, China
}

\begin{abstract}
In recent years, network information has developed rapidly, and the Internet era has come. Under such a big background, management of human resource is also faced with a new change, and compared with the old era, the advent of Internet era means the management of human resource is not only managing the relevant staffs, but also maintain the correspondence with social economy in the process of human resource operation. Under the new circumstance, it is particularly important that opening up and innovating the new thinking of human resource management.
\end{abstract}

Keywords: Internet era; Human resource management; Innovative thinking.

\section{Introduction}

Internet is a symbol of the advent of new era, but under such a big background, no matter whether you accept and acknowledge it or not, it will have an effect on our life and work. For human resource management, the rise and development of Internet is an unprecedented challenge particularly. In the modern society with rapid development of Internet, faced with unknown challenges, enterprises should initiatively explore the new pattern of human resource management to add new vitality to enterprise and optimize the structure of enterprise to guarantee the long-term benign development of enterprise.

\section{The Influence of Internet Era to Human Resource Management}

Development of Internet makes every class and economy organization of society even the whole world connect with each other tightly. Informational development makes the autonomy of people stronger, and communication among people also has new change. Information era makes our cognition with work have changed, not the traditional way of listening to the orders step-by-step any more, but changing to one kind of two-way selection, for example, the communication between bosses and staffs, between clients and staffs. Transparency of information brought by the development of Information can make them express their thought and cognition without obstacles, and daring to think and talk is the direct manifestation of this influence, in short, "commercial democracy".

In the progress of economic globalization, the resource and capital have gradually optimized through continuous improvement and integration. Among them, human resource, as one kind of important manifestation pattern, is bound to be affected to some degree, and this kind of effect is also mutual. Human resource flow expresses certain pattern under the situation of economic globalization, and the change of this kind of pattern brings more or less influence to the development of enterprises even the global economy. Based on this situation, enterprises should give play to the spirit of advancing with the times and forging ahead to greet the enormous challenge brought by the network era. Internet seems like an interactional big circle, and in this circle, every individual and every kind of resource are in the correlative and indispensable condition, where not only mutual cooperation exists but also mutual competition exists. And under such big circumstance, there is no absolute right or wrong, but the settlement and analysis of information and sharing of resource.

Development of network also drove the development of technology, and increasing the support of technology to the new human resource management model will make human resource get more integration, so that meeting varieties of demands of enterprise development. At first, the application of advanced technology will make human resource management proceed with high efficiency, and fully display the efficacy of human resource. Secondly, application of technology will change work style and method of human resource and increase the fitness of enterprise management and human resource management on the basis of science to promote the development of enterprise. In the network era, information spreads rapidly and information content is complex, which has some effect on human 
resource. And as for the influence on this aspect, human resource management is crucial to the exploration and training of informational talents. And only by this way can human resource management can get good development in the reform of new trend.

\section{Innovation of Enterprise in the Internet Era}

Value co-creation of staffs and customers

With the development of times, people's living standard has been gradually increasing, and staffs are the important part of masses of consumers, and their own consumption also plays an instructive role in the consumption of customers. While in the modern society, as consumers, customers not only are consumers, because it is the customers that create the value of enterprises and offer their own feeling and suggestions to enterprises in their consumption process, which expresses the value co-creation of staffs and customers. And it is significant for enterprises to explore the potential value of market. Along with the continuous establishment and improvement of marketing system, establishing the brand effect, enhancing the entire service level, fully integrating resources and ensuring the stability of industrial chain are important parts of enterprise development. Communication of all kinds of aspects will be more fast and convenient in the Internet era, and enterprises can accurately and timely master the market change, which promotes the improvement of entire enterprise, and human resource also get full optimization.

Self-management of staffs

In the new era, the relation between staffs and enterprises has changed. It not only just is the simple relation of dependence, but is that staffs achieve their value through the platform of enterprise. Staffs seek the development for enterprises through their own endeavor, making enterprises thriving, and at the same time of creating value for enterprises, their own value also get promotion. Inner structure of enterprises also has changed in the Internet era, and the entirety appears one kind of net pattern. Staffs also have full right to speak in the enterprise, which makes every staff autonomously work, plan work content and work style. The continuous development of Internet makes the former view of benefit creation has changed to the present view of value creation, and enterprises more focus on the value of creating for enterprises. In such background of great era, rationally allocating and using the resource of company can make it get better development, and the management and application of company resource should surpass the position and grade, making every staff fully give play to their influence and innovating their potential ability.

Pay attention to human capital development and achieve the win-win with monetary capital

As economic strength continuously enhances, development of Internet makes human resource achieve the unprecedented sharing state, and in the synthetic action of knowledge and economy development, there also are new requirement in the aspect of human resource management. Human capital and monetary are the basis of one enterprise creating its value, and only the full optimization and combination of two sides can create higher value. And human resource is one of important elements and the main aspect of enterprise creating value. The priority to development should be embodied no matter for the management of enterprises or the creation of enterprise profit, which leads to the win-win with monetary capital.

\section{New thinking of human resource in the Internet era}

New thinking of human resource content

One of distinct characteristic in the Internet era is information, and both of the fast speed of information and large amount of information spreading are the specific manifestation in the information era. Development of information era makes the information transfer all parts of the country even the whole world more convinent. And another function of Internet is to collect, integrate, analyze and apply the information and data. As can be seen that the innocation aspect of enterprise to the human resource management can be reformed on the basis of Internet. Human resource can be divided into inner resource, peer resource and other resources of company, and it can be synthetically 
studied with the connection of other change and related aspects. In the process of research, the reasonable solution can be made up through the application with some procedures and scientific methods, as well as the mutual combination with two sides to draw some excels or statiscal chart to make more directly analysis. And in the practice, enterprises can make all-round investigation with talents through the Internet, and make rational allocation with talents combining with personal advantages and shortcomings, especially in the aspect of talent recruitment, which will make human resource rationally allocated and get full use rather than wasted or buried. Enterprises also can make analysis with daily life and value of staffs through the Internet, so that they can regulate well enterprise operation system and reasonable salary, which will enhance the working enthusiasm and stability of staffs and make them create more value for company. Internet can analyze the existing problems of enterprise, innovate the management concept of enterprise, make the resource get rational and optimal application and increase the value generated by the enterprise and the economy benefit and social benefit brought by it.

Establish all-round development system of talents

Science and technology are the primary productive forces, and the reseration of knowledge is closely relevant with the development of economy in the Internet era. Under such environment, the comprehensive quality and knowledge ability of enterprise staffs are the important indexes. And it is very important for enterprise to possess excellent talents, which can help enterprise establish all-round talent development system, provide strong human support for enterprises and make the scientificity and feasibility of human resource get guarantee. And as for the manager of human resource, they should fully strengthen their own knowledge reservation so that they can enhance their own management level and bring foreseeable value to enterprise. In addition, they are supposed to have more communication and timely feedback with leaders on the basis of solid work of their own, leading to the obvious enhancing of efficiency and quality of human resource management. And the win-win of enterprises with talents should be achieved on specifically establishing the all-round development system of talents, living up to the perfect combination of individual capital and enterprise capital. There will be all kinds of obstacles in establishing the perfect talent development system, and the sample of emergency processing should be established in the process to solve the emergency. What's more, grass-roots work should be done well on the basis of rational allocation of human resource to make enterprise all-round development.

Realize the self-worth of staffs regarding enterprise as the platform

With the constant penetration of the reform and opening-up policy, democratic concept also have gradually enjoyed support, as for enterprises, the relation of bosses and staffs is mutual selection. In the Internet era, the consumer is dominant part of entire market, and in such condition, the exploration of market and accumulation of customers become the index of staffs creating value. The more value of creation, the more allocation of resource. And the rational allocation of resource can make the inner cost of enterprise sharply reduce and make capable staffs create more value for company. In the modern society, many industries are implementing the salary institution of no basic salary and high commission, which will greatly strengthen the autonomy of staffs and avoid the occurrence of some formalism. The personal ability of staffs get training and promotion, making them constantly broaden the new thinking in the competition and get better development. And at the same time of promoting the individual ability of staffs, their daily emotion and personal requirements should also be paid attention to. Strengthen the awareness of staffs to the enterprise and make staffs deeply penetrate to the whole industry chain of enterprise if necessary, making them more understand the production of enterprise so that they can accomplish their work with ease, which can not only strengthen the integral capabilities but enhance the individual worth.

Perfect the informatization of human resource

Network computer has been more and more universal, nearly in every home, and traditional human resource management cannot make enterprise fully give play to its effect to some degree, even having some negative effect, thus, perfecting the informatization of human resource is extremely urgent. And the informatization of human resource is to reliaze the good cooperation win-win relationship and 
establish the informatization of human resource. Enterprises will implement the managent and allocation with staffs through e-commerce information, and make the corresponding training with them on the basis of accomplishment of work, which will enhance the synthetic service level of staffs and make enterprises efficiently allocate with human resource. Every industry needs innovation, and human resource management is no exception. Sharply innovate the self-dependent innovation ability of staffs and encourage those staffs with innovation concept to make their own potential ability get full play. Although those who are in their position will for their politics, but there should be more probability in the diversified information era. The development of talents cannot be prevented due to the limit of position. And after the all-aspect integration of information, synthesize the personal ability to assess, guarantee the high-quality and high-efficiency play of human resource management effect and make the enterprise go ahead bravely to get more stable and rapid development in the information era.

\section{Conclusion}

In conclusion, the effect of Internet era to human resource work has been more and more serious, and traditional human resource management is affected by the Internet era in all aspects, which requires human resource management to make the transformation and make cautious research with Internet, as a result, the corresponding solution can be made and the human resource management in new era can be more convenient and valid. And the related talents can be systematically trained and dare to subvert tradition and innovate. In other words, in the big ground of Internet information era, only innovating the work method of innovation and exploiting new thinking can make human resource management work valid and give play to its important effect to convoy the development of enterprises.

\section{References}

[1]. Jianfeng Peng. New thinking of human resource management in the Internet era[J]. Chinese human resource exploration, 2014(12):41-48.

[2]. Yilong Liu.New thinking of human resource management in the Internet era[J].Shenhua,2016(14):148. Yilong Liu.

[3]. Jianfeng Peng. New thinking of human resource management in the Internet era[J]. Chinese electricity education, 2014(25):8-11.

[4]. Xinlei Zhu. The thinking of new pattern of human resource management in the Internet era[J]. Reform and management, 2016(2):55.

[5]. Jie Xiong. Location and innovation of human resource management in the Internet era[J]. Modern economy, 2016(4):34-35.

[6]. Xin Sun. New model of human resource management in the Internet era[J]. Chinese collective economy, 2016(13):101-102. 